\title{
Expectativas e Sentimentos de Gestantes Solteiras em Relação aos seus Bebês
}

\author{
Aline Grill Gomes ${ }^{1}$ \\ Sociedade Psicanalitica de Porto Alegre (SPPA) \\ Angela Helena Marin \\ Centro de Ciências da Saúde da Universidade do Vale do Rio dos Sinos, \\ São Leopoldo, RS, Brasil \\ Cesar Augusto Piccinini \\ Rita de Cássia Sobreira Lopes \\ Departamento de Psicologia do Desenvolvimento e da Personalidade \\ da Universidade Federal do Rio Grande do Sul, Porto Alegre, RS, Brasil
}

\section{Resumo}

A gestação é uma experiência complexa para a mulher e vários fatores podem facilitar ou dificultar o transcorrer deste processo. A literatura aponta que o apoio paterno durante a gravidez, pode contribuir para o desenvolvimento psíquico da criança, bem como para a qualidade da relação mãe-bebê. Nesse sentido é plausível pensar que a ausência do apoio paterno pode eventualmente trazer dificuldades para este momento de transição. Assim sendo, o objetivo deste estudo foi investigar os sentimentos e as expectativas das gestantes solteiras em relação aos seus bebês. Participaram nove gestantes primíparas, com idades entre 19 e 28 anos, que estavam no último trimestre de gestação e não apresentavam problemas de saúde. Todas eram solteiras e assumiram a responsabilidade de ter um filho sem a presença do pai biológico ou de outro companheiro que o substituísse. Elas foram entrevistadas individualmente e as suas respostas foram examinadas através de análise de conteúdo qualitativa. Os resultados indicaram que assumir sozinha a responsabilidade por um filho trouxe algum grau de sofrimento para as gestantes e que essa vivência permeou as suas expectativas e sentimentos em relação ao bebê, tanto acerca do sexo, do nome, das características físicas e psicológicas, da sua saúde e da interação mãe-bebê.

Palavras-chave: Gestação, mães solteiras, relação mãe-bebê.

\section{Single Mother's Expectations and Feelings Regarding their Babies}

\begin{abstract}
Pregnancy is a complex experience for the woman and several factors may facilitate or harm the course of this process. The literature suggests that parental support during pregnancy is crucial in psychological development of the child as well as the quality of the mother-infant relationship. In this sense it is plausible to think that the lack of parental support may eventually result in difficulties for this transitional moment. Thus, the aim of this study was to investigate the feelings and expectations of unmarried pregnant women in relation to their babies. Attended nine primiparae aged 19 to 28 years,
\end{abstract}

Endereço para correspondência: Av. Unisinos, 950 - Centro 2, sala E01-109. Bairro Cristo Rei. São Leopoldo, Rio Grande do Sul, Brasil. CEP: 93.022-000. E-mail: algrill7@yahoo.com.br, angelahm@unisinos.br e piccinini@portoweb.com.br

Agência de financiamento: Conselho Nacional de Desenvolvimento Científico e Tecnológico (CNPq). 
who were in the last trimester of pregnancy and had no health problems. All were single and taken responsibility for a child without the presence of the biological father or another partner to replace him. They were interviewed individually and their answers were examined using qualitative content analysis. The results indicated that assume all responsibility for a child brought some degree of distress for pregnant women, and resonances that experience permeated their expectations and feelings about the baby as much concerning sex, the name of the physical and psychological characteristics, their health and mother-infant interaction.

Keywords: Pregnancy, single mothers, mother-baby relationship.

\section{Las Expectativas y los Sentimientos de las Mujeres Solteras Embarazadas en Relación a sus Bebés}

\section{Resumen}

El embarazo es una experiencia compleja para la mujer y varios factores que pueden facilitar o dificultar el curso de este proceso. La literatura sugiere que el apoyo de los padres durante el embarazo es fundamental para el desarrollo psíquico del niño, así como la calidad de la relación madre-hijo. En este sentido, es plausible pensar que la falta de apoyo paterno puede llegar a causar dificultades en este tiempo de transición. Por tanto, el objetivo de este estudio fue investigar los sentimientos y expectativas de las mujeres solteras embarazadas en relación a sus bebés. Participaron nueve primíparas 19-28 año, el último trimestre del embarazo y sin problemas de salud. Todas eran solteras y asumió la responsabilidad de criar a su hijo sin la presencia del padre biológico u otra pareja. Ellos fueron entrevistados individualmente y sus respuestas fueron analizadas mediante análisis de contenido cualitativo. Los resultados indicaron que sea el único responsable de un niño trajo cierto grado de dolor para las mujeres embarazadas, y las resonancias que la experiencia impregnaron sus expectativas y sentimientos acerca del bebé tanto en el sexo, el nombre de las características físicas y psicológicas, su salud y la interacción madre-hijo.

Palabras clave: El embarazo, las madres solteras, la relación madre-bebé.

A gravidez é um período no qual ocorrem mudanças em diversos âmbitos da vida da mulher e representa uma experiência emocional bastante intensa (Brazelton \& Cramer, 1990/1992; Klaus \& Kennel, 1992), pois é um ser vivendo dentro de outro (Raphael-Leff, 1997). Nesse sentido, embora já construindo seu próprio aparato biológico e psíquico, o bebê está completamente dependente da mãe (Solis-Ponton, 2004; Szejer, 1999).

Assim como a puberdade e a menopausa, a gestação é considerada uma crise normativa do ciclo vital, uma vez que as inerentes transformações, tanto relacionais como intrapsíquicas, incitam a revivência de conflitos psicológicos primitivos e podem, inclusive, redimensionar o psiquismo da mulher (Raphael-Leff, 1997; Stern, 1997). Costuma-se dizer que é uma ida sem volta, isto é, uma vez mãe, torna-se im- possível desvencilhar-se deste papel (Szejer \& Stewart, 1997). Sabe-se que as vivências deste momento são sentidas e enfrentadas conforme as características individuais de cada mulher (Solis-Ponton \& Lebovici, 2004).

Além dessas questões pessoais, a gestante se depara com as expectativas e sentimentos que tem acerca do seu bebê, o que complexiza ainda mais todo o processo gravídico. As expectativas da mãe quanto ao bebê originam-se de seu próprio mundo interno, de suas relações passadas e suas necessidades conscientes e inconscientes relacionadas àquele bebê (Brazelton \& Cramer, 1990/1992; Cramer \& Palácio-Espasa, 1993; Lebovici, 1987; Maldonado, 1997; Raphael-Leff, 1997; Soulé, 1987; Stern, 1992, 1997; Szejer \& Stewart, 1997). Introduz-se uma dialética entre o bebê interno e o bebê enquanto objeto externo, ou seja, entre o bebê que a mãe foi ou que 
acredita ter sido e o seu bebê propriamente dito. Essa linha de delimitação, que em alguns casos pode ser tênue, testemunha o trabalho psíquico efetuado pela mãe, que se inicia na gravidez com uma reativação do objeto interno (metáfora de seu passado, de sua infância) para o gradual reconhecimento do bebê enquanto alteridade, tendo uma rede de identificações subjetivas envolvidas (Golse \& Bydlowski, 2002), as quais geram complexos sentimentos e expectativas. Tais expectativas se constituem sobre o bebê imaginário que cada mãe constrói e envolvem, principalmente, o sexo e o nome do bebê, a maneira como ele se movimenta no útero e as características psicológicas que lhes são atribuídas (Szejer \& Stewart, 1997). O confronto deste bebê imaginário com o bebê real ocorre sempre, mesmo em situações em que não há intercorrências. Diante desta dimensão tão profunda que a maternidade alcança, vários fatores podem tanto facilitar como dificultar o transcorrer deste processo. Entre estes fatores é plausível pensar que a ausência do apoio paterno durante a gestação pode eventualmente trazer dificuldades para este momento de transição.

A reflexão acerca da influência da função paterna no desenvolvimento infantil e do quanto à ausência do pai afeta a relação da mãe com a criança, tem ganhado destaque entre alguns autores (Ferrari, 2001; Ramires, 1997). O apoio paterno durante a gravidez e nos primeiros meses de vida do bebê é decisivo no desenvolvimento psíquico da criança, bem como na qualidade da interação mãe-bebê. Brazelton (1981/1988), por exemplo, fez referência ao papel do pai como fonte de ajuda à mãe, destacando que a presença do pai e o reconhecimento de que o bebê também é fruto do seu desejo, auxiliam a mãe a compartilhar a responsabilidade da criação da criança. Isso tende a minimizar os sentimentos maternos de ansiedade e a incapacidade frente a esse novo papel.

Além disso, a figura paterna tem papel importante na construção da relação da mãe com seu bebê (Stern, 1997) e no desenvolvimento de sua função materna (Brazelton \& Cramer, 1990/1992). Nesse sentido, Winnicott $(1965 / 1971)$ já preconizava as ideias de que, se a mãe se sentir amada como mulher pelo pai da criança, ela tende a cumprir mais adequadamente as tarefas de ser mãe. Como disse Bowlby (1989), ser mãe não é um papel fácil de exercer, tendo em vista a quantidade de tempo e a complexa dedicação que os filhos demandam. Para o autor, cuidar e promover a constituição psíquica de uma criança não é tarefa para uma só pessoa, e a assistência de um companheiro pode torná-la mais leve e prazerosa. A função materna e a introdução da função paterna permitem sustentar a dupla inserção do bebê enquanto produto e enquanto alteridade e é justamente esta tensão entre ausência e presença, entre dentro e fora, que permite ao bebê aceder ao processo de subjetivação (Zornig, 2010). Assim, é plausível pensar que ser mãe solteira pode exigir, eventualmente, recursos psíquicos adaptativos (Camacho et al., 2006; McLanahan \& Booth, 1989), pois esta nem sempre conta com a estrutura necessária para o exercício mais tranquilo da maternidade.

Nesse sentido, a solidão e o medo tendem a ser temas frequentes nas histórias sobre a gestação em mães solteiras, bem como o sentimento de vergonha e de segredo, fazendo com que muitas delas relatem a concepção não desejada como um evento traumático em suas vidas (Ellison, 2003). Em um contexto como esse, pode ocorrer uma possível decepção e algum nível de ressentimento em relação ao pai da criança, a sobrecarga com as tarefas de cuidado desta, maior vulnerabilidade a ter dificuldades econômicas e de inserir-se no mercado de trabalho (Clarke-Stewart, Vandell, McCartney, Owen, \& Booth, 2000; Lipman, Boyle, Dooley, \& Offord, 2002). Tais aspectos podem levar ao sofrimento psíquico(Hope, Power, \& Rodgers, 1999), ao aumento de depressão (Cairney, Boyle, Offord, \& Racine, 2003) e até a um maior isolamento social. O isolamento pode, inclusive, reforçar uma relação simbiótica entre a mãe solteira e o seu bebê, destinando a ele funções que, originalmente, seriam atribuídas ao pai. Dessa forma, ela pode esperar que a criança tenha atitudes de cuidado e apoio para com ela e possa atender as suas demandas emocionais (Peris \& Emery, 2005). Esse modelo de relação foi definido por 
Duryea (2008) como parentificação, isto é, atribuição da função parental à criança.

Por outro lado, há autores que criticam a ênfase nos aspectos negativos vinculados a maternidade solitária como podendo levar a dificuldades para a criança e sua relação com a mãe, sublinhando a subjetividade de cada situação (Mannis, 1999; Nair \& Murray, 2005). Portanto, pode-se pensar que o estabelecimento da relação mãe-bebê depende das características psíquicas individuais da mãe e da criança e não somente do contexto no qual vivem.

É importante salientar que nos dias atuais, constata-se um número cada vez maior de famílias uniparentais, que tem, na maioria dos casos, a mãe como progenitor responsável. Isso está ocorrendo em função tanto dos elevados índices de divórcio quanto da opção de muitas mulheres por terem um filho enquanto solteiras, ou seja, da desvinculação entre parentalidade e conjugalidade. Conforme dados do censo realizado pelo Instituto Brasileiro de Geografia e Estatística (IBGE, 2011; www.ibge.gov.br) nos últimos anos houve um expressivo crescimento no número de famílias sob responsabilidade da mulher (atingindo 17,4\%), o que indica uma importante mudança quanto às configurações familiares da sociedade brasileira.

Apesar desta nova realidade, é possível pensar que ser mãe solteira pode implicar uma sobrecarga de tarefas, em especial na gestação e nos primeiros anos de vida da criança, em que o apoio, em especial o paterno, se faz bastante relevante (Dessen \& Braz, 2000). Assim sendo, o objetivo do presente estudo foi investigar os sentimentos e as expectativas das gestantes solteiras em relação aos seus bebês.

\section{Método}

\section{Participantes}

Participaram deste estudo nove gestantes primíparas, no último trimestre de gestação, sem problemas de saúde, com idades entre 19 e 28 anos $(M=23$ anos; $D P=3,1)$. Todas eram solteiras e tiveram uma relação amorosa com o pai da criança antes de engravidar, ou seja, a gravidez não foi ocasional, mas também não foi planeja- da, e elas acabaram por assumir o bebê sem a participação do pai biológico ou de outro companheiro que o substituísse. As participantes eram de níveis socioeconômicos variados e residiam na região metropolitana de Porto Alegre. Em termos de escolaridade, uma gestante tinha ensino fundamental incompleto, duas ensino médio incompleto, cinco ensino médio completo e, uma ensino superior incompleto. Essa variação na escolaridade estava relacionada à diversidade de status ocupacional das gestantes, segundo a escala de Holligshead (1975), alternando entre profissões de "baixo status" (sete das mães estavam em profissões classificadas de 1 a 4) a "alto status" (duas das mães em profissões classificadas de 7 a 9).

A amostra foi selecionada, com base nos critérios descritos acima, dentre os participantes de um estudo maior intitulado Estudo Longitudinal de Porto Alegre: Da Gestação à Escola ELPA (Piccinini, Tudge, Lopes, \& Sperb, 1998), que teve por objetivo investigar tanto os aspectos subjetivos e comportamentais das interações iniciais pai-mãe-bebê, assim como o impacto de fatores iniciais do desenvolvimento nas interações familiares, no comportamento social de crianças pré-escolares e na transição para a escola de ensino fundamental. Este estudo iniciou acompanhando 81 gestantes primíparas que não apresentavam intercorrências clínicas, nem com elas mesmas ou com o bebê e envolveu várias fases de coletas de dados desde a gestação até os sete anos das crianças. O convite inicial para participar do estudo ocorreu quando a gestante fazia pré-natal em hospitais da rede pública da cidade de Porto Alegre (51,2\%), nas unidades sanitárias de saúde do mesmo município (7,3\%), através de anúncio em veículos de comunicação $(26,8 \%)$ e por indicação $(14,6 \%)$. Para fins do presente estudo, foram incluídos todos os casos de gestantes solteiras que participavam do ELPA e foram considerados apenas os dados derivados dos instrumentos aplicados na gestação.

\section{Delineamento, Procedimentos e Instrumentos}

Trata-se de uma pesquisa qualitativa, com delineamento exploratório e transversal, cujo ob- 
jetivo foi investigar os sentimentos e as expectativas das gestantes solteiras em relação aos seus bebês. Seguindo as fases de coleta de dados do ELPA, no terceiro trimestre de gestação, após o contato inicial com a gestante, explicava-se o objetivo do estudo e realizava-se a Entrevista de Contato Inicial (Grupo de Interação Social, Desenvolvimento e Psicopatologia [GIDEP], 1998a), que investigava se a gestante atendia aos critérios de inclusão no estudo, com destaque para sua idade gestacional e seu estado de saúde. Uma vez passada esta etapa, a gestante era visitada em sua residência, quando assinava o Termo de Consentimento Livre e Esclarecido e respondia a Entrevista de Dados Demográficos (GIDEP, 1998b), usada para obter informações demográficas adicionais, tais como idade, escolaridade, estado civil, ocupação, religião e grupo étnico. Além disto, ela era solicitada a responder à Entrevista sobre a Gestação e as Expectativas da Gestante (GIDEP, 1998c). Esta entrevista estruturada era composta de oito conjuntos de questões relacionadas tanto ao bebê como à maternidade e investigava, por exemplo, as percepções da gestante em relação ao planejamento da gravidez, sua aceitação, seu estado de humor predominante, suas percepções e fantasias sobre o bebê e a maternidade, e a relação com o pai do bebê e demais membros de sua família. Para fins do presente estudo foram consideradas apenas as questões relacionadas aos sentimentos e expectativas sobre o bebê. Cada tópico investigado era apresentado inicialmente à gestante em forma de uma questão ampla (Ex.: Eu gostaria que tu me falasses sobre o teu bebê; e Como tu imaginas que vai ser o bebê quando nascer?). Caso a resposta da gestante não fosse muito explícita, eram usadas outras questões que ajudavam a esclarecer os tópicos investigados (Ex.: O que tu já sabes sobre o bebê? Tu já sabes o sexo do bebê? Como tu te sentiste quando soube que era menino/menina? $\mathrm{O}$ que tu gostarias que fosse? Por quê? Tu já pensaste num nome para o bebê? Quem escolheu? Algum motivo para a escolha do nome? Tu sentes o bebê se mexer? Desde quando? Como é que foi? Tu costumas tocar a barriga ou falar com o bebê? Que características físicas tu imaginas que o bebê vai ter? Como tu imaginas que vai ser o temperamento, o jeito dele? Por quê? Com quem tu achas que o bebê vai ser parecido? Por quê? Quais são suas preocupações em relação à saúde do bebê?).

\section{Resultados}

A análise de conteúdo qualitativa (Bardin, 1977; Laville \& Dionne, 1999) foi utilizada para investigar os sentimentos e as expectativas das gestantes solteiras em relação aos seus bebês. Para fins de análise foi utilizada uma estrutura de categorias temáticas derivadas de Piccinini, Gomes, Moreira e Lopes (2004), cuja elaboração original se deu com base na literatura (Raphael-Leff, 1997; Stainton, 1985; Szejer \& Stewart, 1997) e nas respostas das gestantes à entrevista do ELPA utilizada. No presente estudo foram consideradas seis categorias envolvendo os sentimentos e expectativas maternas quanto: (a) ao sexo do bebê, (b) ao nome do bebê; (c) às carac-

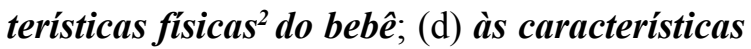
psicológicas do bebê ; (e) à interação mãe-bebê; (f) à saúde do bebê.

Dois dos autores deste estudo classificaram separadamente os relatos das mães em cada categoria e, em casos de discordância, recorreu-se a um terceiro avaliador. Eles também decidiram conjuntamente quais os relatos que melhor ilustravam cada categoria em relação tanto às particularidades como as semelhanças entre os casos. A seguir apresenta-se cada uma das categorias temáticas, ilustrando-as com verbalizações das próprias mães.

\section{Sentimentos e Expectativas em Relação ao Sexo do Bebê}

Essa categoria se refere aos sentimentos e expectativas com relação a ter um menino ou uma menina e o quanto isto teria implicações

2 Esta categoria não está presente no artigo de Piccinini et al. (2004), mas neste estudo foi incluída devido às verbalizações das participantes sobre este tema conterem aspectos relevantes no contexto da relação entre as gestantes solteiras e seus bebês. 
para o relacionamento da díade. As gestantes manifestaram um desejo definido de que o filho fosse de determinado sexo: "É que eu sempre tive vontade e dizia que en queria ter uma filha menina. Menina enfeita mais, arruma, vê um vestidinho e já compra . . . eu fiquei super contente que é uma menina" (G433).

No que diz respeito às implicações quanto ao sexo para os sentimentos da gestante e sua relação com o bebê, as mães referiram que depois de saberem do sexo bebê este se tornou mais personalizado para elas, o que facilitou a relação entre eles: "Ah, depois que a gente sabe o quêé, é bem melhor. Antes ficava falando 'nenê', não sabe se é guri ou se é guria, agora já me refiro a ela, né?" (G8). Também foram relatados sentimentos de aceitação da gravidez e do bebê pelo fato dele ser menina ou menino:

Foi abençoado por Deus! Desde que eu sou-

be que era o meu gurizinho eu sou a mulher mais feliz do mundo. Dei graças a Deus que eu não fiz a besteira de tirar, porque eu ia tá me sentindo a última se eu soubesse que foi o meu filhinho que eu tivesse tirado. (G6)

Para as gestantes, o sexo do bebê pareceu que poderia lhes assegurar um determinado lugar na família: "Ai quando ela disse que era um gurizinho, dai eu disse: pô lá na minha família só tem mulher, um gurizinho não ia fazer mal, né? [risos]. Vai ser bom!" (G2); e na relação com elas: "Eu fiquei super feliz de pensar que é uma menininha, porque talvez seja mais companheira" (G3). Por outro lado, o sexo do bebê foi percebido como um risco de repetição de comportamentos da mãe considerados por ela como negativos:

Eu tinha medo de ter uma filha mulher porque eu pensava que se ela se apaixonar e acontecer o mesmo que aconteceu comigo, como é que eu vou fazer? Eu ficava pensando "ah, eu só sei falar de mágoa, de coisa ruim de relacionamento amoroso", a mu-

3 A letra e o número entre parênteses identificam a participante que forneceu o relato. Os relatos foram, eventualmente, editados para reduzir sua extensão, mas sem que isto comprometesse seu conteúdo. lher sempre tem uma expectativa, sonha, já o homem não sonha tanto. (G1)

\section{Sentimentos e Expectativas em Relação ao Nome do Bebê}

Essa categoria diz respeito aos sentimentos e expectativas em relação ao nome do bebê. Foram manifestados diversos aspectos que envolveram a escolha e o significado do nome do bebê para a relação mãe-bebê. Dentre estes, as gestantes destacaram algumas características do nome, como o fato de o acharem bonito: "Não tem um motivo especial, eu achava Pedro 4 um nome bonito, eu gostava" (G1). Outro motivo da escolha do nome do bebê foi o significado atribuído a ele, como uma homenagem a alguém especial:

Lauro. Porque eu acho bonito, e Heitor por ser o nome do meu pai. Botei porque eu gosto muito do meu pai, o meu pai sempre foi bom pra mim né, nunca me condenou por eu tá grávida. Então eu resolvi homenagear ele. (G9)

Ou por remeter a algo: "É o nome do anjinho do meu signo" (G2). Além disso, o nome foi escolhido por envolver uma expectativa relacionada às características psicológicas que as gestantes esperavam que seus filhos tivessem: "É um nome forte, parece nome de pessoa decidida" (G6).

\section{Sentimentos e Expectativas em Relação às Características Físicas}

Essa categoria diz respeito aos sentimentos $\mathrm{e}$ às expectativas quanto às características físicas imaginadas para o bebê. As gestantes destacaram impressões de que o bebê seria parecido com elas mesmas. As gestantes destacaram impressões de que o bebê seria parecido consigo mesma: "Eu imagino ela bem pequeninha . . . é que quando eu nasci eu era uma coisinha, um ratinho" (G3); ou com o pai: "Eu imagino ela parecida com ele [pai do bebê], não comigo. Ele é moreno, mais alto que eu, moreno claro, as-

4 Os nomes próprios mencionados são fictícios a fim de preservar a identidade dos participantes. 
sim, cabelo preto, olhos castanhos. Eu imagino que ele vai ser assim" (G8).

Por outro lado, elas expressaram seus desejos sobre com quem gostariam que o bebê se parecesse. Houve relatos demonstrando o desejo que fosse parecido com elas: "A gente tem aquela imagem, eu queria que ele fosse de olhos claros que nem eu, que puxasse parecido comigo, né?" (G2). Já sobre o bebê ser parecido com o pai, as gestantes relataram o desejo tanto de que isso acontecesse: "Eu quero muito que ela tenha o olho claro, porque ele tem o olho bem claro, verde, então o meu sonho é que ela tenha olho claro" (G3); quanto de que ele não tivesse quaisquer semelhanças com o pai: "Tudo que eu não queria é que ele fosse assim, redondinho igualzinho ao do pai. Fiquei até triste quando eu vi [na eco]" (G1).

\section{Sentimentos e Expectativas em Relação às Características Psicológicas}

Essa categoria se refere aos sentimentos e expectativas em relação às características psicológicas imaginadas para o bebê. As impressões foram baseadas tanto no comportamento do bebê naquele momento: "Às vezes eu fico muito tempo de pé, ele fica chutando, chutando, chutando. Pelo jeito, acho que ele vai ser bem brabo, sabe, assim, bem brabinho" (G1); quanto no seu próprio comportamento, considerando este como capaz de influenciar o estado psíquico do bebê: "Eu acho que ele vai ser uma criança calma, porque a minha gestação inteira, eu procurei ao máximo ficar tranquila, não me incomodar, não me estressar com as coisas" (G6).

As gestantes também manifestaram impressões de que o bebê tivesse características psicológicas semelhantes às de suas famílias de origem: "Vai ser brabinho assim. Aqui em casa, tem bastante gente braba também, então não tem jeito, acho que o jeito dele é puxar os brabinho da família" (G1); ou a ela própria e ao pai: "Não vai ser muito bom de gênio porque eu sou muito irritada, muito gritona, muito mandona e ele [o pai] também é assim" (G7).

As mães ainda ressaltaram o desejo de o bebê apresentar uma determinada característica psicológica: "Espero que seja uma criança bem calminha, que não seja muito agitada e que não dê muito trabalho" (G4). Também apareceu o descontentamento caso o bebê fosse parecido com o pai: "Eu não queria, mas eu não posso fazer nada se ele vai ser parecido com o pai, irritadinho" (G1).

\section{Sentimentos e Expectativas em Relação à Interação Mãe-Bebê}

Essa categoria compreende o modo como ocorre a interação mãe-bebê ainda na gestação, e os sentimentos e expectativas das gestantes envolvidos nesta relação. As gestantes referiram que a sua interação com o filho ocorria através de conversas que elas tinham com ele:

Então eu fico conversando: "A mãe fez isso, isso, isso para o teu pai, mas independente de a gente voltar ou não a mãe gosta muito de ti, a mãe te quis e por isso que tu tá aqui!" Eu converso muita coisa, muita coisa, às vezes eu vou dormir cinco horas da manhã de tanto falar! (G7)

Da percepção dos movimentos fetais e do toque na barriga:

No começo é estranho, tu sente uma coisa muito boa por dentro, uma coisa diferente, uma harmonia diferente, mas é estranho. Não dá para negar que é estranho tu sentir que tem uma coisinha mexendo assim dentro da tua barriga. Mas é bom, é muito bom. (G3)

"Eu acho tri bom, fico mexendo nos pés dele enquanto ele faz isso. Eu começo a pegar nos pés e fazer cócegas" (G6); e da ecografia: "Foi legal. Chorei, me emocionei porque é diferente. Uma coisa é tu saber que tu tá grávida, a outra é tu ver o bebê" (G6).

\section{Sentimentos e Expectativas quanto à Saúde do Bebê}

Nessa categoria foram incluídos os sentimentos e as expectativas das gestantes com relação à saúde do bebê. Elas referiram preocupações quanto ao desenvolvimento saudável do bebê:

Eu fiquei pensando: será que vai nascer bem? Vai nascer normal? Minha preocupa- 
ção é essa. Eu fiz uma ecografia e a doutora disse que tava tudo bem, só que não dava para ver detalhadamente os dedinhos, a orelhinha. Esse que é o meu medo. (G2)

Outras já demonstraram maior tranquilidade em razão de estarem cuidando da sua saúde: "Eu acho que ela vai nascer bem saudável, porque eu como muita fruta, verdura, nunca mais fumei" (G8).

\section{Discussão}

O presente estudo teve como objetivo investigar os sentimentos e as expectativas das gestantes solteiras em relação aos seus bebês. Os resultados revelaram que tais gestantes manifestaram uma preferência definida por um dos sexos, mesmo sendo primíparas, o que não corrobora as ideias apresentadas por alguns autores (Villeneuve, Laroche, Lippman, \& Marrache, 1988; Wu \& Eichmann, 1988). Eles referem que, em geral, as mães primíparas não costumam ter ou expressar uma predileção sobre o sexo do bebê, justamente por ainda não terem filhos. No caso das gestantes solteiras, é plausível pensar que por estarem em uma posição mais vulnerável psiquicamente, podem ver no sexo do bebê uma possibilidade de reasseguramento da aceitação da gravidez por parte da sua família, como se este pudesse facilitar na instauração de um lugar de valor para ela e para o bebê e, com isso, reforçar a rede de apoio, que está falha pela ausência do pai. Além disso, a preferência por um dos sexos também pode estar relacionada às identificações intrapsíquicas estabelecidas ao longo da vida da gestante, seja ela solteira ou casada (Golse, 2002; Golse \& Bydlowski, 2002; Lebovici, 1987; Stern, 1992, 1997).

Dependendo dessa psicodinâmica, o sexo masculino e o feminino podem ter várias representações e significados para a gestante, uma vez que está ligado também à elaboração da feminilidade e do complexo edípico (Bydlowski, 2002; Freud, 1924/1969). O masculino, por exemplo, pode representar a compensação da ausência do companheiro, dando a sensação de plenitude ou a perpetuação da frustração já vivida com o pai do bebê. Já o sexo feminino pode tanto oportu- nizar uma revivência da relação dual com a mãe, permitindo que a gestante se sinta acompanhada, como representar a ameaça de que a filha venha a repetir a sua história (Golse, 2002). De qualquer modo, tanto as gestantes solteiras do presente estudo como as casadas investigadas por Piccinini et al. (2004), referiram que depois de terem conhecimento do sexo bebê este se tornou mais personalizado para elas, o que facilitou a relação da díade.

Sobre os sentimentos e expectativas em relação ao nome do bebê, as gestantes destacaram que a escolha se deu em função da preferência e gosto por um nome específico ou devido às características psicológicas às quais o nome remetia. Destacou-se a escolha por um nome forte, o que possivelmente faz pensar no desejo de que os filhos sejam crianças capazes de suportar a falta do pai e a consequente fragilidade da mãe (Marin, Gomes, Lopes, \& Piccinini, 2011; Szejer, 1999). Foi mencionada ainda a escolha do nome pelo significado que este possui para a gestante, como, por exemplo, o nome de um anjo, o que pode estar relacionado à ideia de proteção.

Percebe-se que as gestantes deste estudo manifestaram um desejo de homenagear seu próprio pai, sendo que uma delas explicitou que seria uma forma de agradecimento por não ter se sentido criticada pela condição de mãe solteira. Com isso, pareciam pretender manter seus pais mais próximos da dupla, como uma possibilidade de referência da figura masculina (Wall, José, $\&$ Correia, 2002).

Quanto aos sentimentos e expectativas comuns em relação às características físicas do bebê, foram destacados impressões e desejos de que ele fosse parecido com a própria gestante ou com o pai do bebê. Ser parecido com a mãe pode significar a continuidade da linhagem familiar materna e de reforçar a relação entre a díade ou também remeter a uma ideia de ser recompensada pelo fato de ser a principal responsável pela criança, que assumiu e irá educá-la. Freud (1914/1969) já vinculava o desejo de ter um filho ao desejo narcísico de imortalidade e, nesse sentido, os filhos serem parecidos com os pais atende, muitas vezes, essa realização narcísica. 
Além disso, o desejo da gestante de que fosse parecido consigo mesma, pode estar associado a uma solução para a castração por seu estatuto ilusório de completude narcísica (Zornig, 2010), em que nada ou ninguém seja necessário, nem mesmo um pai, o que pode também afastar o medo materno de um dia a criança querer procurá-lo. Wall et al. (2002) destacaram o risco de isolamento da criança na família monoparental, por vezes devido ao sofrimento causado por conflitos vividos entre a sua mãe e o seu pai, e apontaram para o quanto isso pode não ser saudável para o desenvolvimento da criança.

Já o fato de algumas das gestantes expressarem expectativas do bebê ser parecido com o pai, pode estar representando o desejo de aproximação e de garantia da paternidade e de uma imagem não promiscua da mãe, especialmente entre as participantes do presente estudo, que relataram que tiveram um relacionamento afetivo com o pai do bebê, anterior a gestação. Isso nem sempre é o que ocorre entre as mães solteiras e vale lembrar que os encontros sexuais muitas vezes acontecem sem comprometimento afetivo, o que tem sido bastante comum no contexto atual de relacionamentos. Portanto, uma gravidez sem a presença do pai pode levar a julgamentos sociais preconceituosos, associados à promiscuidade, descuido da saúde, e impulsividade, o que pode intensificar as dificuldades próprias de uma gestação. Por outro lado, pelo menos uma das gestantes também manifestou o desejo de que o bebê não fosse parecido com o pai, o que possivelmente denota seus sentimentos de tristeza, raiva, decepção e ressentimento pela sua ausência. As características físicas do bebê semelhantes ao pai podem constantemente remeter a mãe à história de fracasso da relação conjugal.

Particularidades quanto às características psicológicas do bebê também foram relatadas, como, por exemplo, expectativas de que a criança siga tendo um padrão de comportamento percebido na gestação. Também foram manifestadas as expectativas de que o seu próprio comportamento como mãe na gestação influenciaria o estado psíquico do bebê. Esses achados corroboram o estudo de Piccinini et al. (2004) que verificou as mesmas expectativas em gestantes casadas que também consideraram o comportamento intra-útero do bebê como um prelúdio para suas características psicológicas. Além disso, essas gestantes relacionavam o seu estado psíquico durante a gravidez como um fator importante para a constituição psíquica do bebê, inclusive, em alguns momentos, cuidando para manterem uma gestação tranquila. Percebe-se, assim, que a maternidade envolve uma situação subjetiva, que acaba não dependendo exclusivamente do tipo de configuração familiar, como ser solteira ou casada, e afirmações nessa direção podem ser meros preconceitos.

No que diz respeito às expectativas e sentimentos acerca da interação mãe-bebê, as gestantes referiram que estas ocorriam através das percepções dos movimentos fetais e do toque na barriga, através da visualização do bebê na ecografia, bem como em conversas com o bebê. Percebeu-se que estas últimas referiam-se à questões relativas à ausência do pai e ao reasseguramento do amor materno. Tais conversas podem também ser entendidas como uma busca da mãe para elaborar a conflitiva vivida com o pai do bebê, além de consolidar a sua relação com a criança. Isso pode trazer ganho para a relação da díade, e por isso contribuir para minimizar as consequências do conflito entre os pais, e melhorar o desenvolvimento emocional da criança (Clarke-Stewart et al., 2000; Finger, Hans, Bernstein, \& Cox, 2009).

Por fim, sobre as expectativas e sentimentos quanto à saúde do bebê apareceram relatos indicando preocupações quanto ao desenvolvimento do bebê estar saudável, bem como o sentimento de tranquilidade das gestantes em razão de estarem cuidando da sua própria saúde. Uma vez que a gestação é um período de formação do bebê, é esperado que existisse certa preocupação com o desenvolvimento do bebê, o que denota a presença de vínculo da mãe com o bebê. Entre tantas incertezas, o que está ao alcance da mãe para diminuir seu sentimento de impotência é o cuidado que ela pode tomar com sua saúde física e psicológica. Portanto, cuidar-se é algo que a mãe pode controlar, uma postura ativa que ela 
pode decidir assumir, o que, consequentemente, traz tranquilidade acerca do bem-estar do bebê. Esses dados também corroboram os achados de Piccinini et al. (2004) que encontraram estes mesmos sentimentos em relação à saúde do bebê entre gestantes casadas.

Em conjunto, os resultados desse estudo levam a pensar que a maternidade por si só implica uma experiência complexa psiquicamente, e que as mães solteiras, por vezes, tendem a vivenciá-la com maiores dificuldades, as quais já se manifestam desde a gestação. Isso porque sentimentos de desilusão e ressentimento da mãe podem permear todo o processo de gestação, deixando, muitas vezes, marcas de tristeza, desesperança, insegurança e irritabilidade. Além disso, assumir a responsabilidade por um filho sozinha, não é uma situação simples e fácil e pode estar associada a sofrimento por ser diferente de um ideal social, que também pode fazer parte da subjetividade da própria gestante. Isto é, ver-se e deixar-se ver como sendo uma mãe solteira pode se constituir em uma vivência difícil para a mulher. Ressonâncias dessa vivência permearam as expectativas e sentimentos em relação ao bebê das gestantes do presente estudo e estas abrangeram diversos aspectos investigados como o sexo e o nome do bebê, suas características, sua saúde e a interação mãe-bebê.

Contudo, é importante sublinhar que o fato de ser uma mãe solteira e ter algumas expectativas, sentimentos e vivências mais difíceis não implicam necessariamente em um impacto negativo para a relação dela com o bebê e para a constituição psíquica da criança. Isso eventualmente pode até se tornar um problema na presença de outras questões individuais e/ou sociais, que venham a potencializar a vulnerabilidade psíquica e as dificuldades inerentes à situação.

Nesse sentido, sabe-se que a maternidade solteira tem sido cada vez mais frequente na sociedade ocidental, tendo em vista o papel que a mulher vem ocupando, caracterizado por uma maior independência e autonomia. Além disso, as configurações familiares estão bastante diversas, impactando e refletindo diferentes dinâmicas psíquicas dos membros envolvidos. Percebe-se também uma maior fragilidade quan- to ao comprometimento das pessoas tanto em relação à conjugalidade como à parentalidade (Jablonski, 2005). A relação de consanguinidade ou de união não é mais suficiente para assegurar o exercício da parentalidade e a contemporaneidade, ao incitar uma ruptura entre conjugalidade e parentalidade, demonstra que esta última deixa de ser o principal objetivo da estrutura familiar.

Uma vez que a atualidade comporta um borramento de referenciais simbólicos estáveis e uma pluralização das leis e de possibilidades de subjetivação, "tornar-se mãe" ou "tornar-se pai" passou a depender em maior grau da história individual e do desejo de cada um dos genitores do que de um modelo de família nuclear tradicional (Julien, 2000; Roudinesco, 2003; Zornig, 2010). Decorrente disso destaca-se a importância de se estudar estas diversas e novas lógicas psíquicas que estão embasando a parentalidade, como, por exemplo, as mães solteiras.

No entanto, ainda são poucas as pesquisas nacionais sobre estes temas, o que sinaliza para a necessidade de que novos estudos sejam realizados para entender, por exemplo, como as mães solteiras tendem a lidar com os desafios desse contexto e que fatores podem ajudar no estabelecimento de uma relação mãe-bebê próxima e saudável. Nesse sentido, é importante que equipes de saúde estejam atentas a essa situação, tanto na gestação como nos primeiros anos de vida da criança que são os mais importantes para a constituição psíquica do bebê. Isto se faz particularmente necessário em situações de carência econômica, social e afetiva, que podem exacerbar, expressivamente, as dificuldades encontradas pelas mães solteiras. Espera-se que esse estudo desperte nos psicólogos e demais profissionais de saúde interesse pelo assunto para que se dediquem ao relevante trabalho de acompanhar as mães, especialmente as solteiras que apresentem alguns riscos com relação à construção da sua maternidade e de sua relação com o filho.

\section{Referências}

Bardin, L. (1977). Análise de conteúdo. Lisboa, Portugal: Edições 70. 
Bowlby, J. (1989). O cuidado com as crianças (S. M. de Barros, Trad.). Uma base segura: Implicações clínicas da teoria do apego (pp. 17-32). Porto Alegre, RS: Artes Médicas.

Brazelton, T. B. (1988). Gravidez: O nascimento do apego (D. Batista, Trad.). In T. B. Brazelton, $O$ desenvolvimento do apego: Uma família em formação (pp. 15-50). Porto Alegre, RS: Artes Médicas. (Original publicado em 1981)

Brazelton, T. B., \& Cramer, B. G. (1992). A formação do apego no pai (M. B. Cipolla, Trad.). In T. B. Brazelton \& B. G. Cramer (Eds.), As primeiras relações (pp. 39-50). São Paulo, SP: Martins Fontes. (Original publicado em 1990)

Bydlowski, M. (2002). O olhar interior da mulher grávida: Transparência psíquica e representação do objeto interno. In L. Corrêa Filho, M. Corrêa Girade, \& P. França (Eds.), Novos olhares sobre a gestação e a criança até três anos: Saúde perinatal, educação e desenvolvimento do bebê (pp. 205-214). Brasília, DF: LGE.

Cairney, J., Boyle, M., Offord, D. R., \& Racine, Y. (2003). Stress, social support and depression in single and married mothers. Social Psychiatry and Psychiatric Epidemiology, 38, 442-449. doi:10.1007/s00127-003-0661-0

Camacho, R. S., Cantinelli, F. S., Ribeiro, C. S., Cantilino, A. Y., Gonsales, B. K., Braguittoni, \& E., Rennó, J., Jr. (2006). Transtornos psiquiátricos na gestação e no puerpério: Classsificação, diagnóstico e tratamento. Revista de Psiquiatria Clínica, 33(2), 92-102. doi:10.1590/S010160832006000200009

Clarke-Stewart, K. A., Vandell, D. L., McCartney, K., Owen, M. T., \& Booth, C. (2000). Effects of parental separation and divorce on very young children. Journal of Family Psychology, 14, 304-326. doi:10.1037/0893-3200.14.2.304

Cramer, B., \& Palácio-Espasa, F. (1993). Técnicas psicoterápicas mãe/bebê. Porto Alegre, RS: Artes Médicas.

Dessen, M., \& Braz, M. (2000). Rede social de apoio durante transições familiares decorrentes do nascimento de filhos. Psicologia: Teoria $e$ Pesquisa, 16, 221-231.

Duryea, M. M. (2008). Mothers with chronic physical illness and the parentification of their children. Dissertation Abstracts International: Section B: The Sciences and Engineering, 69, 714.
Ellison, M. A. (2003). Authoritative knowledge and single women's unintentional pregnancies, abortions, adoption, and single motherhood: Social stigma and structural violence. Medical Anthropology Quarterly, 17(3), 322-347. doi:10.1525/ maq.2003.17.3.322

Ferrari, H. (2001). A ausência paterna e suas implicações na qualidade da interação mãe-bebê (Dissertação de mestrado não publicada, Curso de Pós-Graduação em Psicologia do Desenvolvimento, Universidade Federal do Rio Grande do Sul, Porto Alegre, RS, Brasil).

Finger, B., Hans, S. L., Bernstein, V. J., \& Cox, S. M. (2009). Parent relationship quality and infantmother attachment. Attachment \& Human Development, 11,285-306. doi:10.1080/1461673 0902814960

Freud, S. (1969). A dissolução do Complexo de Édipo (M. A. M. Rego, Trad.). In J. Salomão (Ed.), Edição standard brasileira de obras completas de Sigmund Freud (Vol. 19, pp. 193-199). Rio de Janeiro, RJ: Imago. (Original publicado em 1924)

Freud, S. (1969). Introdução ao narcisismo (M. A. M. Rego, Trad.). In J. Salomão (Ed.), Edição standard brasileira de obras completas de Sigmund Freud (Vol. 14). Rio de Janeiro, RJ: Imago. (Original publicado em 1914)

Golse, B. (2002). Depressão do bebê, depressão da mãe, conceito de psiquiatria perinatal. In L. Corrêa Filho, M. Corrêa Girade, \& P. França (Eds.), Novos olhares sobre a gestação e a criança até três anos: Saúde perinatal, educação e desenvolvimento do bebê (pp. 232248). Brasília, DF: LGE.

Golse, B., \& Bydlowski, M. (2002). Da transparência psíquica à preocupação materna primária: Uma via de objetalização. In L. Corrêa Filho, M. Corrêa Girade, \& P. França (Eds.), Novos olhares sobre a gestação e a criança até três anos: Saúde perinatal, educação e desenvolvimento do bebê (pp. 215-220). Brasília, DF: LGE.

Grupo de Interação Social, Desenvolvimento e Psicopatologia. (1998a). Ficha de Contato Inicial: Dados demográficos da gestante. Porto Alegre, RS: Universidade Federal do Rio Grande do Sul.

Grupo de Interação Social, Desenvolvimento e Psicopatologia. (1998b). Entrevista de dados demográficos da gestante. Porto Alegre, RS: Universidade Federal do Rio Grande do Sul. 
Grupo de Interação Social, Desenvolvimento e Psicopatologia. (1998c). Entrevista sobre a gestação e as expectativas da gestante. Porto Alegre, RS: Universidade Federal do Rio Grande do Sul.

Holligshead, A. (1975). Four factor index of social status. Unpublished manuscript, Yale University, New Haven, CT, United States.

Hope, S., Power, C., \& Rodgers, B. (1999). Does financial hardship account for elevated psychological distress in lone mothers? Social Science \& Medicine, 49(12), 1637-1649. doi:10.1016/ S0277-9536(99)00251-8

Instituto Brasileiro de Geografia e Estatística. (2011). Censo demográfico 2010. Recuperado em http:// www.ibge.gov.br/home/estatistica/populacao/ censo2010/default.shtm

Jablonski, B. (2005). Atitudes de jovens solteiros frente à família e ao casamento: Novas tendências? In T. Feres-Carneiro, Família e casal: Efeitos da contemporaneidade (pp. 93-110). Rio de Janeiro, RJ: Editora da Pontifícia Universidade Católica do Rio de Janeiro.

Julien, P. (2000). Abandonarás teu pai e tua mãe. Rio de Janeiro, RJ: Cia de Freud.

Klaus, M., \& Kennel, J. (1992). Pais/bebê: A formação do apego. Porto Alegre, RS: Artes Médicas.

Laville, C., \& Dionne, J. (1999). A construção do saber: Manual de metodologia da pesquisa em Ciências Humanas. Porto Alegre, RS: Artes Médicas.

Lebovici, S. (1987). O bebê, a mãe e o psicanalista. Porto Alegre, RS: Artes Médicas.

Lipman, E. L., Boyle, M. H., Dooley, M. D., \& Offord, D. R. (2002). Child well being in singlemother families. Journal of the American Academy of Child and Adolescent Psychiatry, 41(1), 75-82.

Maldonado, M. (1997). Psicologia da gravidez. Petrópolis, RJ: Vozes.

Mannis, V. S. (1999). Single mothers by choice. Family Relations, 48(2), 121-128.

Marin, A. H., Gomes, A. G., Lopes, R. C. S., \& Piccinini, C. A. (2011). A constituição da maternidade em gestantes solteiras. Psico, 42(2), 246-254.

McLanahan, S., \& Booth, K. (1989). Mother-only families: Problems, prospects, and politics. Journal of Marriage and the Family, 51(3), 557580. doi: $10.2307 / 352157$
Nair, H., \& Murray, A. D. (2005). Predictors of attachment security in preschool children from intact and divorced families. The Journal of Genetic Psychology: Research and Theory on Human Development, 166, 245-263.

Peris, T. S., \& Emery, R. E. (2005). Redefining the parent-child relationship following divorce: Examining the risk for boundary dissolution. Journal of Emotional Abuse, 5, 169-189. doi:10.1300/J135v05n04_01

Piccinini, C. A., Gomes, A. G., Moreira, L. E., \& Lopes, R. C. S. (2004). Expectativas e sentimentos da gestante em relação ao seu bebê. Psicologia: Teoria e Pesquisa, 20(3), 223-232. doi:10.1590/ S0102-37722004000300003

Piccinini, C. A., Tudge, J., Lopes, R. C., \& Sperb, T. (1998). Estudo longitudinal de Porto Alegre: Da gestação à escola. Projeto de Pesquisa, Universidade Federal do Rio Grande do Sul, Porto Alegre, RS, Brasil.

Ramires, V. R. (1997). A paternidade está em mutação. In V. R. Ramires, O exercício da paternidade hoje (pp. 112-117). Rio de Janeiro, RJ: Rosa dos Tempos.

Raphael-Leff, J. (1997). Gravidez: A história interior. Porto Alegre, RS: Artes Médicas.

Roudinesco, E. (2003). A familia em desordem. Rio de Janeiro, RJ: Jorge Zahar.

Solis-Ponton, L. (2004). La parentalidad: desafio para el tercer milênio - un homenaje internacional a Serge Lebovici. México, DF: Editorial El Manual Moderno.

Solis-Ponton, L., \& Lebovici, S. (2004). Diálogo Leticia Solis-Ponton - Serge Lebovici. In L. Solis-Ponton, La parentalid: desafio para el tercer milenio - un homenaje internacional a Serge Lebovici (pp. 3-10). Mexico, DF: Editorial El Manual Moderno.

Soulé, M. (1987). O filho da cabeça, o filho imaginário. In T. Brazelton, B. Cramer, L. Kreisler, R. Schappi, \& M. Soulé (Eds.), A dinâmica do bebê (pp. 132-170). Porto Alegre, RS: Artes Médicas.

Stainton, M. (1985). The fetus: A growing member of the family. Family Relations, 34, 321-326.

Stake, R. E. (1994). Case Studies. In N. Denzin \& Y. Lincoln (Eds.), Handbook of qualitative research (pp. 236-247). London: Sage.

Stern, D. (1992). O mundo interpessoal do bebê. Porto Alegre, RS: Artes Médicas. 
Stern, D. (1997). A constelação da maternidade. Porto Alegre, RS: Artes Médicas.

Szejer, M. (1999). Palavras para nascer: A escuta psicanalítica na maternidade. São Paulo, SP: Casa do Psicólogo.

Szejer, M., \& Stewart, R. (1997). Nove meses na vida da mulher. São Paulo, SP: Casa do Psicólogo.

Villeneuve, C., Laroche, C., Lippman, A., \& Marrache, M. (1988). Psychological aspects of ultrasound imaging during pregnancy. Canadian Journal of Psychiatry, 33(6), 530-535.

Wall, K., José, S. J., \& Correia, S. V. (2002). Mães sós e cuidados às crianças. Análise Social, $37(163), 631-663$.

Winnicott, D. W. (1971). E o pai? (A. Cabral, Trad.). In D. W. Winnicott, A criança e o seu mundo (2. ed., pp. 127-133). Rio de Janeiro, RJ: Zahar. (Original publicado em 1965)
Wu, J., \& Eichmann, A. (1988). Fetal sex identification and prenatal bonding. Psychological Reports, 63(1), 199-202. doi:10.2466/ pr0.1988.63.1.199

Zornig, S. (2010). Tornar-se pai, tornar-se mãe: O processo de construção da parentalidade. Tempo Psicanalítico, 42(2), 453-470.
Recebido: $05 / 08 / 2013$

$1^{a}$ revisão: $17 / 02 / 2014$ Aceite final: $25 / 08 / 2014$ 